\title{
31P Nuclear Magnetic Resonance Measurements of Muscle Glucose-6-Phosphate \\ Evidence for Reduced Insulin-dependent Muscle Glucose Transport or Phosphorylation Activity in Non-Insulin-dependent Diabetes Mellitus
}

Douglas L. Rothman, Robert G. Shulman, ${ }^{\star}$ and Gerald I. Shulman

Departments of Internal Medicine and ${ }^{*}$ Molecular Biophysics and Biochemistry, Yale University School of Medicine, New Haven, Connecticut 06510

\begin{abstract}
To assess the rate-limiting step in muscle glycogen synthesis in non-insulin-dependent diabetes mellitus (NIDDM), the concentration of glucose-6-phosphate (G6P) was measured by ${ }^{31} P$ nuclear magnetic resonance (NMR) during a hyperglycemichyperinsulinemic clamp. Six subjects with NIDDM and six age weight-matched controls were studied at similar steady-state plasma concentrations of insulin ( $\sim 450 \mathrm{pmol} / \mathrm{liter})$ and glucose (11 mmol/liter). The concentration of G6P in the gastrocnemius muscle was measured by ${ }^{31} \mathrm{P}$ NMR. Whole-body oxidative and nonoxidative glucose metabolism was determined by the insulin-glucose clamp technique in conjunction with indirect calorimetry. Nonoxidative glucose metabolism, which under these conditions is a measure of muscle glycogen synthesis (1990. N. Engl. J. Med. 322:223-228), was $31 \pm 7 \mu \mathrm{mol} /(\mathrm{kg}$ body wt-min) in the normal subjects and $13 \pm 3 \mu \mathrm{mol} /(\mathrm{kg}$ body wt-min) in the NIDDM subjects $(P<0.05)$. The concentration of $\mathrm{G6P}$ was higher $(0.24 \pm 0.02 \mathrm{mmol} / \mathrm{kg}$ muscle $)$ in the normal subjects than in the NIDDM subjects $(0.17 \pm 0.02, P<0.01)$. Increasing insulin concentrations to insulin 8,500 pmol/liter in four NIDDM subjects restored the glucose uptake rate and G6P concentrations to normal levels. In conclusion, the lower concentration of G6P in the diabetic subjects despite a decreased rate of nonoxidative glucose metabolism is consistent with a defect in muscle glucose transport or phosphorylation reducing the rate of muscle glycogen synthesis. (J. Clin. Invest. 1992. 89:1069-1075.) Key words: glucose clamp • glycogen synthase $\bullet$ insulin resistance $\bullet$ muscle glycogen synthesis $\bullet$ nonoxidative glucose metabolism
\end{abstract}

\section{Introduction}

In a recent study we demonstrated by using ${ }^{13} \mathrm{C}$ nuclear magnetic resonance (NMR) ${ }^{1}$ that, under conditions of a hypergly-

Address reprint requests to Dr. Gerald I. Shulman, FMP 104, Department of Internal Medicine, Yale University School of Medicine, 333 Cedar Street, New Haven, CT 06510.

Received for publication 5 August 1991 and in revised form 12 November 1991.

1. Abbreviations used in this paper: G6P, glucose-6-phosphate; NIDDM, non-insulin-dependent diabetes mellitus; NMR, nuclear magnetic resonance; $\mathrm{PCr}$, phosphocreatine; $\mathrm{Pi}$, intracellular phosphate; RMS, root mean square.

J. Clin. Invest.

(C) The American Society for Clinical Investigation, Inc. 0021-9738/92/04/1069/07 \$2.00

Volume 89, April 1992, 1069-1075 cemic-hyperinsulinemic clamp, nonoxidative glucose metabolism in both normal subjects and subjects with non-insulin-dependent diabetes mellitus (NIDDM) is quantitatively accounted for by muscle glycogen synthesis (1). This confirmed and extended earlier indirect measurements which showed that most of the glucose metabolized was stored nonoxidatively in peripheral tissue but had not identified the storage compound (2-4). The results indicate that under hyperglycemic-hyperinsulinemic conditions a reduced rate of muscle glycogen synthesis is primarily responsible for the slower glucose disposal in NIDDM.

The enzymatic reactions that may be responsible for the reduced insulin-stimulated muscle glycogen synthesis rate in NIDDM are shown schematically in Fig. 1. Muscle glucose transport and glycogen synthase are both insulin stimulated, and each has separately been suggested to be responsible for the reduced rate of insulin-stimulated glucose disposal in NIDDM. Synthase activity measured in biopsy samples has been shown to be lower in subjects with NIDDM than in normal subjects (5-8). Glucose transport activity has been difficult to assess in muscle. Evidence for defective glucose transport in NIDDM muscle comes primarily from studies of cultured adipocytes (9-11), which express the insulin-sensitive GLUT 4 transporter also found in muscle (12).

As a result of its location between the transport and synthase enzymes in the pathway of glycogen synthesis (see Fig. 1), the concentration of muscle glucose-6-phosphate (G6P) is sensitive to the relative activities of these enzymes and the rate of glycolysis. If under hyperglycemic-hyperinsulinemic conditions glycogen synthase is the only enzyme with reduced activity in NIDDM, the initial rate of glucose entry into the G6P pool would be the same in normal and diabetic subjects, and the slower removal of G6P in diabetic subjects owing to reduced muscle glycogen synthesis (1) would result in a higher concentration of G6P. Similar or lower concentrations of G6P in NIDDM would imply that the activity of muscle glucose transport or hexokinase is reduced.

Measurements of human muscle G6P have been made by biopsy under hyperinsulinemic conditions $(13,14)$. However, it has recently been suggested based on studies of rats that concentrations of G6P measured in human biopsies are artifactually high because of glycogen breakdown during the delay between sample excision and freezing (15). An alternate method of measuring human muscle G6P that does not suffer from autolytic artifacts is ${ }^{31} \mathrm{P}$ NMR $(16,17)$. In the present study we have performed ${ }^{31} \mathrm{P}$ NMR measurements of G6P in the gastrocnemius muscle in subjects with NIDDM and ageand weight-matched normal controls under the same conditions of hyperglycemic hyperinsulinemia in order to assess the relative roles of glucose transport and glycogen synthase in the reduced muscle glycogen synthesis rate observed in NIDDM. 


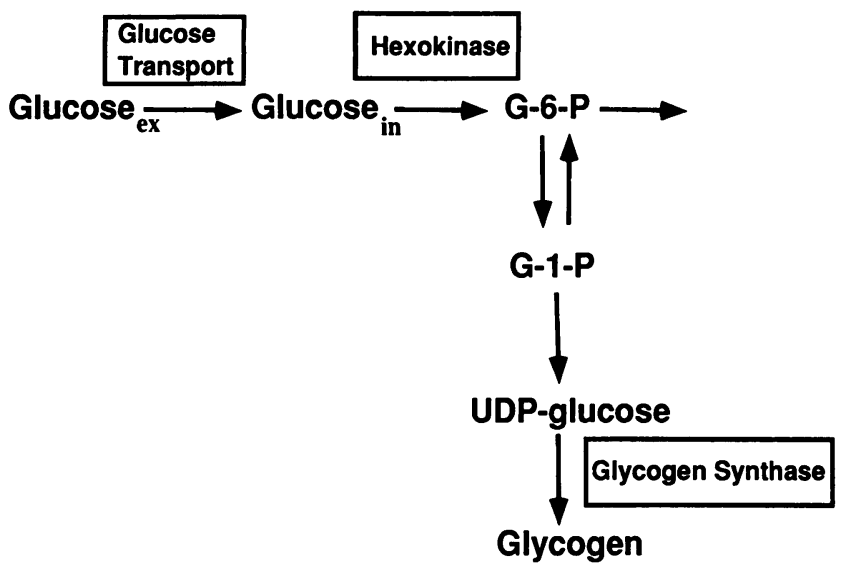

Figure 1. Schematic metabolic pathway for the conversion of extracellular glucose to muscle glycogen. The glucose transporter and hexokinase and glycogen synthase enzymes have been proposed as rate-limiting steps for muscle glycogen synthesis in NIDDM.

\section{Methods}

\section{Subjects}

Six men with NIDDM and six healthy men matched to the diabetic subjects for age and weight were studied. All subjects were within $20 \%$ of their ideal body weight according to the 1959 Metropolitan Life Insurance tables. The mean ( $\pm \mathrm{SD}$ ) weights in the diabetic and normal subjects were $83.5 \pm 7.7$ and $83.3 \pm 6.6 \mathrm{~kg}$, respectively; their mean ages were $62 \pm 5$ and $56 \pm 4$ yr. The mean duration of diabetes, calculated from the first record of a plasma glucose concentration $>7.8 \mathrm{mmol} /$ liter $(140 \mathrm{mg} / \mathrm{dl})$, was $14 \mathrm{yr}$. All the diabetic subjects fulfilled the criteria for the diagnosis of diabetes mellitus as established by the National Diabetes Data Group (18). All of them had been treated with oral sulfonylurea agents; their medication was discontinued at least $7 \mathrm{~d}$ before the study. Their mean hemoglobin $A_{l c}$ level was $13.7 \pm 2.6 \%$ (normal range, 4-8\%), and their mean fasting plasma glucose concentration after the discontinuation of medication was $14.1 \pm 3.4 \mathrm{mmol} /$ liter. No subject had a major disease other than diabetes mellitus or was taking other medications. None of the normal subjects had a family history of diabetes.

Informed consent was obtained from all subjects after the purpose, nature, and potential risks of the study were explained to them. The protocol was reviewed and approved by the Human Investigation Committee of the Yale University School of Medicine.

\section{Experimental protocol}

All studies were begun at 8 a.m. after an overnight fast of 12-14 h. A teflon catheter was inserted into a antecubital vein in each arm to permit blood to be drawn and for infusion. The clamp was started after 40 min of ${ }^{31} \mathrm{P}$ NMR spectroscopy for determining basal metabolite concentrations.

\section{Hyperglycemic-hyperinsulinemic clamp procedure}

Low-dose insulin clamp. Hyperglycemic hyperinsulinemia was induced with the insulin-glucose clamp technique (19). The clamp levels of plasma glucose and insulin were chosen to be similar to the levels achieved in an earlier study in which the muscle glycogen synthesis rate was measured by ${ }^{13} \mathrm{C}$ NMR (1). To inhibit endogenous insulin secretion, an infusion of somatostatin $[0.1 \mu \mathrm{g} /(\mathrm{kg}$ body wt-min)] was initiated $5 \mathrm{~min}$ before the start of the insulin infusion in both the normal and diabetic subjects and continued for $120 \mathrm{~min}$. At time zero, insulin (Humulin, Eli Lilly \& Co., Indianapolis) was administered in a priming dose of $240 \mathrm{pmol} /\left[\mathrm{m}^{2}\right.$ of body surface area-min] followed by a continuous infusion [1 $\mathrm{mU} /(\mathrm{kg}-\mathrm{min})]$ to raise the plasma insulin concentration acutely and maintain it at $\sim 450 \mathrm{pmol} / \mathrm{liter}$. At the same time a vari- able priming infusion of glucose was begun to maintain plasma glucose levels at $\sim 11 \mathrm{mmol} /$ liter for $120 \mathrm{~min}$. The plasma glucose concentration was measured every $5 \mathrm{~min}$ and a variable infusion of a glucose solution $(1.11 \mathrm{M})$ was periodically adjusted to maintain the desired hyperglycemic plateau. Under the hyperglycemic-hyperinsulinemic conditions of the clamp, hepatic glucose production is completely suppressed $(1,20)$. The mean glucose infusion rate, minus urinary glucose excretion, was used to measure the total amount of glucose metabolized.

High-dose insulin clamp. In four of the NIDDM subjects a highdose insulin clamp was performed which was the same as the first protocol except that insulin was infused with a priming dose of 2,400 $\mathrm{pmol} /\left(\mathrm{m}^{2}\right.$ of body surface area-min) followed by a continuous infusion [10 mU/(kg-min)] in order to achieve maximal levels of insulin stimulation. This procedure was performed at the end of a low dose insulin clamp in two of the subjects.

\section{Measurement of respiratory exchange}

Continuous indirect calorimetry was performed during the low insulin clamp studies to determine total-body glucose oxidation at 40-60 and $100-120 \mathrm{~min}$ as previously described $(1,2,21)$. Nonoxidative glucose metabolism was calculated by subtracting the amount of glucose oxidized from the total amount of glucose infused minus glucose excreted in the urine.

\section{Analytical procedures}

Plasma glucose was measured every 5 min (glucose analyzer; Beckman Instruments, Inc., Fullerton, CA). Plasma $\mathrm{PO}_{4}^{-}$was measured every 20-30 min by using an automated analyzer (Hitachi, Tokyo, Japan). Plasma insulin was measured every $20-30 \mathrm{~min}$ as previously described (22).

\section{NMR spectroscopy}

Throughout the study the subjects remained supine within an ORSBruker NMR spectrometer (1-m bore, 2.1 T; Bruker Instruments, Inc., Billerica, MA); the gastrocnemius muscle of the right leg was positioned within the homogeneous volume of the magnet on top of a ${ }^{1} \mathrm{H}-{ }^{31} \mathrm{P}$ concentric surface coil probe. The leg was secured with Velcro straps and a foam foot holder to minimize motion during the experiment. The surface coils, used for both transmitting and receiving, consisted of an inner coil with a 9-cm diam, which was used for ${ }^{31} \mathrm{P}$ acquisition, and an outer coil with a $13-\mathrm{cm}$ diam, which was used for ${ }^{1} \mathrm{H}$ acquisition and decoupling. The magnet was shimmed using the ${ }^{1} \mathrm{H}$ coil. The ${ }^{31} \mathrm{P}$ pulse angle was calibrated using a removable $2-\mathrm{cm}$ diam sphere at coil center containing concentrated $\mathrm{H}_{3} \mathrm{PO}_{4}$. Spectra were obtained using a $70^{\circ}$ pulse at coil center $(100 \mu \mathrm{s})$. A repetition time of $2 \mathrm{~s}$ was used with a 256 -ms acquisition time. During acquisition ${ }^{1} \mathrm{H}$ power ( $1 \mathrm{~W}$ ) was applied at the position of the $\mathrm{C} 6$ protons of $\mathrm{G} 6 \mathrm{P}$ to decouple the $J_{\text {H-P }}$ interaction. Spectra were acquired in 288 scans with $4 \mathrm{k}$ of data points. Time domain data was apodized by using an exponential function giving either $2-$ or $10-\mathrm{Hz}$ line broadening and a mild $500-\mathrm{Hz}$ profile correction (23) and were zero filled to $16 \mathrm{k}$.

Concentrations of metabolites were calculated by comparing resonance areas to the area of the $\beta$ resonance of ATP in the baseline spectrum. A concentration of $5.5 \mathrm{mmol} /(\mathrm{kg}$ muscle) was assumed for ATP (24). Changes in the concentration of G6P and other metabolites during the clamp were determined in difference spectra. To maximize measurement sensitivity the G6P resonance amplitude was measured in each 10-min difference spectrum. An amplitude to intensity conversion factor was obtained for G6P by integrating the sum of four to eight difference spectra. A fully relaxed spectrum (20-s repetition rate, 32 scans) was obtained at the end of each study to correct for $T_{1}$ saturation. In cases where a fully relaxed spectrum was not obtained, an average correction factor was used. The intracellular $\mathrm{pH}$ was calculated from the difference in chemical shift between intracellular phosphate (Pi) and phosphocreatine ( $\mathrm{PCr}$ ) by using the titration curve of Petroff et al. (25) assuming an intracellular concentration of $1.0 \mathrm{mmol} /$ liter free 
$\mathrm{Mg}^{2+}$ (26). The concentration of ADP was estimated from the creatine kinase reaction equilibrium constant (26) assuming $1.0 \mathrm{mmol} /$ liter free $\mathrm{Mg}^{2+}, 30 \mathrm{mmol} /(\mathrm{kg}$ muscle) total creatine (24), and an equilibrium constant of $1.66 \times 10^{9}(26)$.

Although the chemical shift of G6P has been previously measured in extracts and in solution (16), we repeated these measurements to obtain accurate chemical shifts relative to $\mathrm{PCr}$ at the $\mathrm{pH}$ and ionic strengths characteristic of human muscle. Chemical shifts relative to $\mathrm{PCr}$ at $0.00 \mathrm{ppm}$ of 7.16 and $7.08 \mathrm{ppm}$ were measured for the $\beta$ and $\alpha$ anomers of $\mathrm{G} 6 \mathrm{P}$ at the muscle $\mathrm{pH}$ of 7.05 in a solution containing 155 $\mathrm{mmol} /$ liter KCl, $5 \mathrm{mmol} /$ liter G6P, $5 \mathrm{mmol} /$ liter $\alpha$-glycerol phosphate, $10 \mathrm{mmol} / \mathrm{liter} \mathrm{PO}_{4}, 5 \mathrm{mmol} /$ liter $\mathrm{PCr}$, and $5 \mathrm{mmol} /$ liter EDTA at $8.5 \mathrm{~T}$ in a spectrometer (model AM 360, Bruker Instruments, Inc., Billerica, MA). The small chemical shift difference between the resonances of the $\beta$ and $\alpha$ anomers was less than the linewidth in muscle so that a weighted average of the two resonant frequencies of $7.13 \mathrm{ppm}$ was used for the G6P assignment. Based on muscle biopsy assays the only compound of significant concentration with a similar chemical shift to the G6P resonance is $\alpha$-glycerol phosphate which was measured in the same solution as G6P to have a chemical shift of $6.92 \mathrm{ppm}$.

The basal G6P concentration was determined by integrating over the chemical shift range of 7.43-7.13 ppm and multiplying the area by 2 in order to minimize contributions from the upfield (lower ppm) phosphomonoester resonances. The increase in the G6P resonance during the clamp studies was cleanly resolved in the difference spectra with a chemical shift of $7.13 \mathrm{ppm}$, which is significantly different than the chemical shift of $\alpha$-glycerol phosphate. The precision of the G6P concentration measurement in the difference spectra was determined from measurements on each subject of the root mean square (RMS) amplitude variation in the NMR spectrum due to spectral noise. The RMS amplitude variation due to noise, which is independent of signal intensity, was calculated as one-fifth of the maximum peak to peak amplitude variation in a $1-\mathrm{kHz}$ bandwidth in the spectrum (100 times the $\mathrm{G} 6 \mathrm{P}$ resonance bandwidth) not containing resonances. The average RMS noise would result in a 1 SD variation in the measured G6P concentration of $0.015 \mathrm{mmol} /(\mathrm{kg}$-muscle) in a 40 -min difference spectrum with a range between subjects of $0.009-0.030 \mathrm{mmol} /(\mathrm{kg}-\mathrm{muscle})$. A second potential source of error in the G6P measurement was variations in intensity owing to spectrometer instability which would result in subtraction errors in the difference spectra. Spectrometer stability was assessed from the residual intensity of the ATP resonances in each difference spectrum and the subtraction accuracy in all cases was better than $1 \%$. With this accuracy the measured $0.12 \mathrm{mmol} /(\mathrm{kg}$-muscle) resting $\mathrm{G} 6 \mathrm{P}$ concentration would result in a variation in intensity between scans of $<0.0012 \mathrm{mmol} /(\mathrm{kg}$-muscle), which is 10-fold less than the variation due to RMS noise. In several cases the precision of measuring the G6P concentration in the baseline spectra was assessed by comparison of successive spectra obtained from the same subject and found to vary by close to what was predicted from RMS noise. However, because of potential overlap with neighboring phosphomonoester resonances, the basal G6P concentration measurement must be considered a maximum estimate.

\section{Statistics}

Except where indicated measurements are given as the group mean with the standard error of the measurement. $P$ values were determined by using the unpaired student two-tailed $t$ test.

\section{Results}

Low-dose insulin clamp. The mean initial plasma glucose concentration was $5.5 \pm 0.1 \mathrm{mmol} /$ liter in the normal subjects and $14.1 \pm 1.4 \mathrm{mmol} / \mathrm{liter}$ in the diabetic subjects. The basal plasma $\mathrm{PO}_{4}$ concentration was $3.3 \pm 0.3 \mathrm{mmol} /$ liter in the normal subjects and $3.9 \pm 0.3 \mathrm{mmol} / \mathrm{liter}$ in the diabetic subjects. After the start of hyperglycemic-hyperinsulinemic clamp in the normal subjects, the glucose concentration was rapidly raised and within 40 min maintained at a stable mean value of $11.0 \pm 0.1$ $\mathrm{mmol} / \mathrm{liter}$. In the NIDDM subjects the plasma glucose concentration decreased after the insulin infusion and then maintained by glucose infusion at a similar mean value of $10.9 \pm 0.6$ $\mathrm{mmol} / \mathrm{liter}$. The initial plasma insulin levels were $80 \pm 12 \mathrm{pmol} /$ liter in the normal group and $69 \pm 12 \mathrm{pmol} /$ liter in the diabetic group. During the clamp the plasma insulin concentrations rose rapidly and within 10 min reached a mean plateau value of $456 \pm 36 \mathrm{pmol} / \mathrm{liter}$ in the normal subjects and $462 \pm 36 \mathrm{pmol} /$ liter in the diabetic subjects, respectively.

In the $60-120-\mathrm{min}$ period the total-body glucose uptake rate was $50 \pm 6 \mu \mathrm{mol} /(\mathrm{kg}$ body wt-min) in the normal subjects and $23 \pm 3 \mu \mathrm{mol} /(\mathrm{kg}-\mathrm{min}$ ) (Table $\mathrm{I}, P<0.01$ ) in the diabetic subjects. The majority of the glucose uptake in both groups was accounted for by nonoxidative glucose metabolism, the rate of which was higher in the normal subjects [ $31 \pm 7 \mu \mathrm{mol} /(\mathrm{kg}$ body wt-min), $n=5]$ than in the diabetic subjects [ $13 \pm 3 \mu \mathrm{mol} /(\mathrm{kg}$ body wt-min), $n=4 ; P<0.05$ ]. The rate of total-body glucose oxidation was $14 \pm 1 \mu \mathrm{mol} /(\mathrm{kg}$ body wt-min) in the normal subjects and $9 \pm 1 \mu \mathrm{mol} /(\mathrm{kg}$ body wt-min) in the diabetic subjects $(P<0.01)$.

Fig. 2 shows ${ }^{31} \mathrm{P}$ NMR spectra obtained from a normal subject before and during the clamp. Resonances observed in the spectrum are assigned to G6P, Pi, PCr, and ATP. The difference spectrum between the baseline spectrum and a spectrum obtained during the clamp shows that during the glucoseinsulin infusion there was an increase in G6P (7.13 ppm) and $\mathrm{Pi}(4.88 \mathrm{ppm})$ and a decrease in $\mathrm{PCr}(0.00 \mathrm{ppm})$. The decrease in the $\mathrm{PCr}$ resonance as assessed by integration is within measurement accuracy the same as the sum of the increase in the G6P and Pi resonances.

The basal G6P concentrations were similar at $0.12 \pm 0.01$ $\mathrm{mmol} /(\mathrm{kg}-\mathrm{muscle})$ in the normal and $0.13 \pm 0.01 \mathrm{mmol} /(\mathrm{kg}-$ muscle) in the diabetic subjects. The time course of G6P concentration during the glucose-insulin infusion is shown in Fig. 3 for the normal and diabetic subjects. The mean G6P concentration rose in the normal subjects to a steady state value of $0.24 \pm 0.01 \mathrm{mmol} /(\mathrm{kg}$-muscle) by $25 \mathrm{~min}$ into the infusion. An increase in G6P over basal levels was observed in each of the normal subjects. The subjects with NIDDM had a lower mean G6P concentration during the clamp of $0.17 \pm 0.01 \mathrm{mmol} /(\mathrm{kg}-$ muscle) $(P<0.01)$.

Table I. Glucose Metabolism in Normal and Diabetic Subjects during Low-Dose Hyperglycemic-Hyperinsulinemic Clamp Studies

\begin{tabular}{lccc}
\hline & \multicolumn{3}{c}{ Whole-body glucose metabolism } \\
\cline { 2 - 4 } Study group & Total & Oxidative & Nonoxidative \\
\hline \multirow{3}{*}{ Nomol/kg body wt-min } \\
Normal subjects & $50 \pm 6$ & $14 \pm 1^{*}$ & $31 \pm 7^{*}$ \\
Diabetic subjects & $(n=6)$ & $(n=5)$ & $(n=5)$ \\
& $23 \pm 3$ & $9 \pm 1^{*}$ & $13 \pm 3^{*}$ \\
$P$ value & $(n=6)$ & $(n=4)$ & $(n=4)$ \\
& $<0.01$ & $<0.01$ & $<0.05$ \\
\hline
\end{tabular}

Values are mean \pm SE.

* Indirect calorimetry was performed on five of the normal subjects and four of the diabetic subjects. 


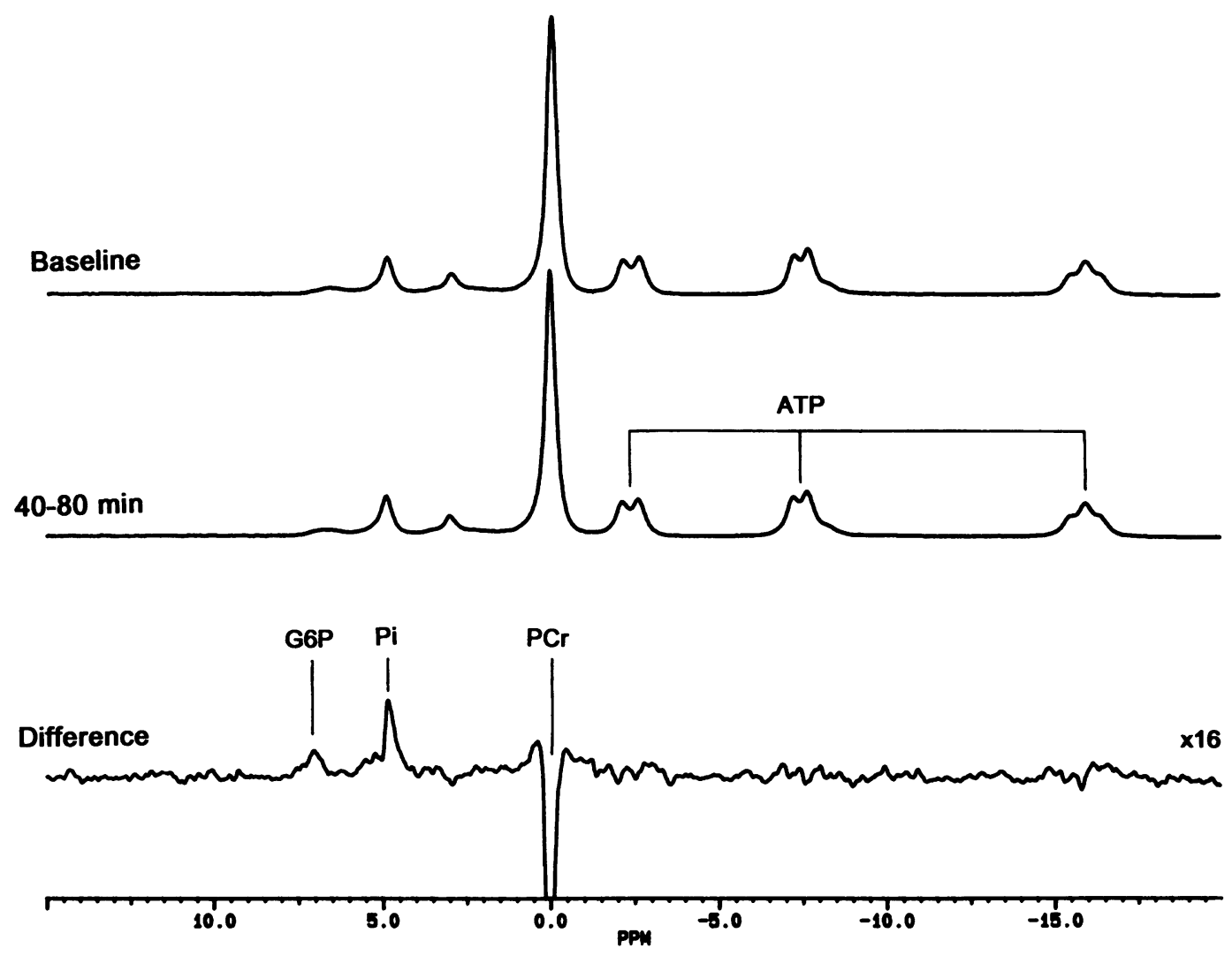

Figure 2. ${ }^{31} \mathrm{P}$ NMR spectra of the gastrocnemius muscle of a normal subject. A baseline spectrum and a spectrum acquired over the period of 40-80 min into the low-dose insulin clamp are shown as well as the difference between these two spectra. In the difference spectrum (clamp minus baseline), an increase during the clamp is observed of the resonances of G6P (7.13 ppm) and Pi (4.88 ppm). The increase is quantitatively accounted for by a decrease in $\mathrm{PCr}(0.00$ ppm), which is not completely shown in the plot owing to its greater resonance amplitude. The increase in the G6P resonance intensity corresponds to a 0.13 $\mathrm{mmol} /(\mathrm{kg}-$ muscle) increase in concentration.
The mean basal concentrations of muscle metabolites determined from the ${ }^{31} \mathrm{P}$ NMR spectra are given in Table II. No significant differences between the normal and diabetic subjects were observed in the basal concentrations of G6P, ADP, $\mathrm{Pi}, \mathrm{PCr}$, and muscle $\mathrm{pH}$. The mean values of the muscle metabolite concentrations averaged over the 40-100-min period of the clamp are listed in Table III. The muscle Pi concentration increased within 10-20 min of the start of the glucose-insulin infusion in both groups and reached a similar steady-state value within $60 \mathrm{~min}$. There was a small decline in plasma $\mathrm{PO}_{4}$ concentration of $0.4 \pm 0.1 \mathrm{mmol} /$ liter in the normal subjects and $0.3 \pm 0.1 \mathrm{mmol} /$ liter in the diabetic subjects. However, the

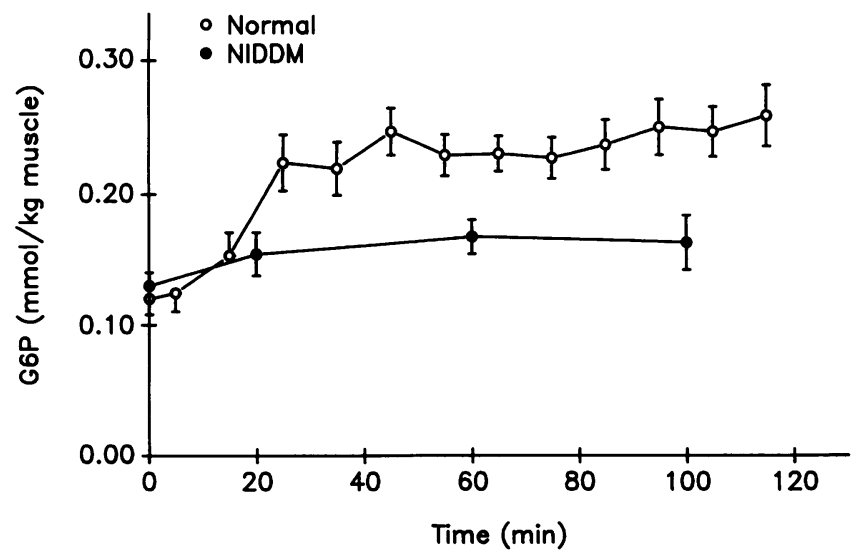

Figure 3. Time course of the mean muscle G6P concentration ( \pm SE) during the low-dose insulin clamp for the normal (O) subjects and the subjects with NIDDM (๑). The NIDDM subjects are shown at lower time resolution ( $40 \mathrm{~min}$ ) to obtain better sensitivity. increase in $\mathrm{Pi}$ and G6P concentration could be accounted for almost entirely by a decrease in the PCr concentration (Table III). From the measured decrease in $\mathrm{PCr}$ a small increase in ADP concentration was calculated from the creatine kinase equilibrium which was similar for both groups (Table III).

High-dose insulin clamp. For the four NIDDM subjects studied at the higher insulin infusion rate the mean steady-state plasma glucose concentration was $9.8 \pm 0.5 \mathrm{mmol} /$ liter and the mean plasma insulin concentration was $8,480 \pm 1,260 \mathrm{pmol} /$ liter. The rate of total body glucose uptake was $65 \pm 9 \mu \mathrm{mol} /(\mathrm{kg}$ body wt-min), which was significantly higher than for subjects with NIDDM at the low dose insulin clamp $(P<0.001)$ and similar to the glucose uptake rate (Table I) of the normal subjects. As shown in Fig. 4, for each subject the muscle G6P concentration and glucose uptake rate measured in the highdose insulin clamp was greater than in the low-dose insulin clamp. The average G6P concentration was $0.22 \pm 0.03 \mathrm{mmol} /$ (kg-muscle), which is similar to the G6P concentration of the normal subjects in the low-dose insulin study. Other metabolite concentrations measured by ${ }^{31} \mathrm{P}$ NMR during the study were similar to the concentrations in the low-dose insulin study.

\section{Discussion}

The results of this study are consistent with subjects with NIDDM having reduced insulin-stimulated activity in either muscle glucose transport or glucose phosphorylation by hexokinase. The basis of this conclusion is as follows. The flow out of the muscle G6P pool is given by the sum of the rates of muscle glycogen synthesis and muscle glycolysis. Under the hyperglycemic-hyperinsulinemic conditions of this study, the rate of 
Table II. Basal Muscle Metabolite Concentrations Measured by ${ }^{31} P$ NMR in Normal and Diabetic Subjects

\begin{tabular}{|c|c|c|c|c|c|}
\hline Study group & G6P & $\mathrm{Pi}$ & $\mathrm{PCr}$ & ADP & $\mathrm{pH}$ \\
\hline & & & $\mathrm{mmol} / \mathrm{kg}-\mathrm{musc}$ & & \\
\hline $\begin{array}{l}\text { Normal subjects } \\
\quad(n=6)\end{array}$ & $0.12 \pm 0.01$ & $3.01 \pm 0.17$ & $22.70 \pm 0.36$ & $0.055 \pm 0.001$ & $7.06 \pm 0.01$ \\
\hline $\begin{array}{l}\text { Diabetic subjects } \\
\quad(n=6)\end{array}$ & $0.13 \pm 0.01$ & $3.31 \pm 0.17$ & $24.26 \pm 0.75$ & $0.050 \pm 0.002$ & $7.04 \pm 0.01$ \\
\hline
\end{tabular}

nonoxidative glucose metabolism is almost entirely accounted for by muscle glycogen synthesis (1), which indicates that the rate of muscle glycogen synthesis was more than two times higher in the normal subjects. If the only defect in muscle glycogen synthesis in NIDDM is the glycogen synthase enzyme, then upon insulin stimulation the initial rate of inflow of glucose into the G6P pool would be the same as in the normal subjects. However, the steady-state level of G6P in the subjects with NIDDM would be higher than in the normal subjects owing to the need to reduce the rate of inflow through hexokinase by allosteric inhibition (27) to match the reduced rate of outflow from the G6P pool due to the lower rate of glycogen synthesis. The experimental finding of a lower steady-state G6P concentration in the diabetic subjects is therefore inconsistent with the reduced rate of glycogen synthesis as being entirely due to reduced synthase activity and indicates that the activity of either or both glucose transport and hexokinase is reduced in NIDDM.

The conclusion of reduced glucose transport/hexokinase activity would not be valid if despite a reduced rate of glycogen synthesis the total rate of outflow from the G6P pool was actually greater in the diabetic subjects owing to an enhanced muscle glycolytic rate. However, this is not likely because an increase in glycolytic lactate production would be included in the measured rate of nonoxidative glucose metabolism which was significantly lower in the subjects with NIDDM. Furthermore, virtually all of the nonoxidative metabolism in both normal subjects and subjects with NIDDM can be attributed to muscle glycogen synthesis under these conditions (1). A higher rate of oxidative glycolysis would be reflected by an increase in total body glucose oxidation but this rate was also significantly lower in the diabetic subjects.

An alternate explanation of the lower muscle G6P concentration in subjects with NIDDM during the low-dose insulin study is that other inhibitors of the hexokinase reaction were elevated relative to their concentrations in normal subjects.
Based on in vitro studies the main effectors of the rate of muscle hexokinase other than G6P are Pi, pH, ATP, and ADP (27). These compounds were measured in the ${ }^{31} \mathrm{P}$ NMR spectra and found to have similar concentrations in diabetic and normal subjects (Table III) during the low dose clamp.

Our results are in contrast with previous biopsy measurements of G6P in human muscle under conditions of euglycemic hyperinsulinemia where no change (14) or a slight decrease (13) in G6P concentration was observed with increasing rates of nonoxidative glucose metabolism. The concentration of muscle G6P measured by ${ }^{31} \mathrm{P}$ NMR under basal and high insulin conditions was approximately three to five times lower than measured in previous human biopsy studies $(13,14,24,28)$ but similar to concentrations found in rapid in situ freezing studies of animal muscle $(15,29,30)$. A limitation of the biopsy technique is that the tissue must be excised before being frozen during which time glycogenolysis may substantially raise the G6P concentration. In a study by Rossetti and Giacarri (15) when rat muscle freezing was delayed for several seconds, which is similar to the time between excision and freezing for human muscle biopsies, the G6P concentration increased by three- to fourfold, which is a possible explanation for the higher G6P concentrations measured in prior human studies.

An $\sim 20 \%$ increase in Pi concentration was observed in both normal and diabetic subjects during the glucose-insulin infusion. While some of this increase could be attributed to transport of inorganic phosphate from the plasma space, the sum of the increase in Pi and G6P can be accounted for almost entirely by a decrease in the concentration of PCr. The increase in Pi may reflect increased muscle oxidative ATP production (31) owing to the energy expenditure needed for glycogen synthesis. However, the increase in Pi was similar in the normal and diabetic subjects despite the normals having a more than twofold greater muscle glycogen synthesis rate, which implies that other factors may be responsible for the increase.

Although the finding of lower muscle G6P concentration in

Table III. Muscle Metabolite Concentrations Measured by ${ }^{31} P$ NMR in Normal and Diabetic Subjects during Low Dose Hyperglycemic-Hyperinsulinemic Clamp Studies

\begin{tabular}{|c|c|c|c|c|c|c|c|c|}
\hline Study group & G6P & $\mathrm{Pi}$ & $\mathrm{PCr}$ & $\Delta$ G6P & $\Delta \mathrm{Pi}$ & $\Delta \mathrm{PCr}$ & ADP & $\mathrm{pH}$ \\
\hline & \multicolumn{8}{|c|}{ mmol/(kg-muscle) } \\
\hline \multicolumn{9}{|l|}{ Normals } \\
\hline$(n=6)$ & $0.24 \pm 0.02$ & $3.66 \pm 0.22$ & $21.97 \pm 0.31$ & $0.12 \pm 0.01$ & $0.64 \pm 0.09$ & $-0.74 \pm 0.06$ & $0.057 \pm 0.001$ & $7.06 \pm 0.01$ \\
\hline \multicolumn{9}{|l|}{ Diabetics } \\
\hline$(n=6)$ & $0.17 \pm 0.02$ & $3.94 \pm 0.25$ & $23.55 \pm 0.80$ & $0.04 \pm 0.01$ & $0.62 \pm 0.11$ & $-0.71 \pm 0.09$ & $0.053 \pm 0.001$ & $7.05 \pm 0.01$ \\
\hline$P$ value & $<0.01$ & NS & NS & $<0.001$ & NS & NS & NS & NS \\
\hline
\end{tabular}




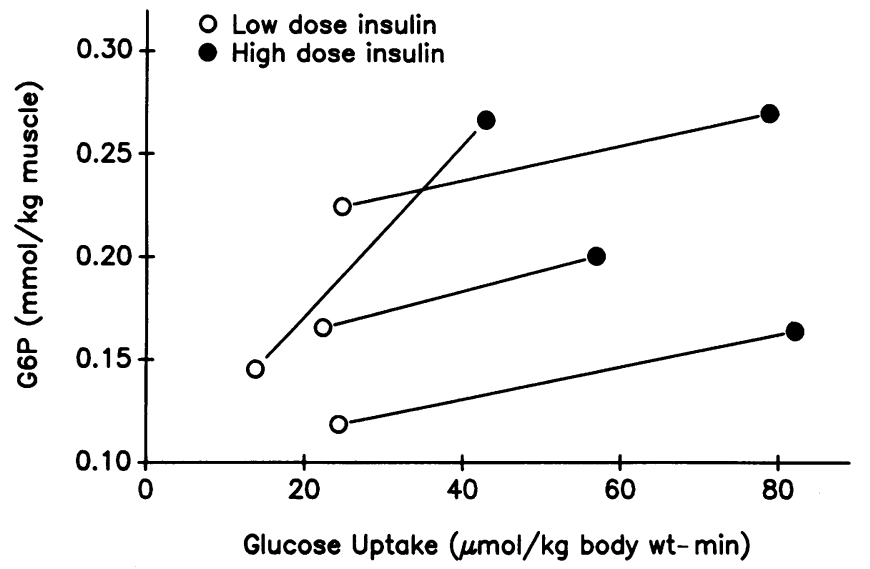

Figure 4. Plot of glucose uptake rate versus G6P concentration for each of the subjects with NIDDM who were studied in both a low insulin dose (0) and high insulin dose (•) clamp. In each subject an increase in both G6P concentration and glucose uptake rate was observed in the high insulin dose clamp. A line connects the data from each subject.

NIDDM is consistent with a reduction in transport/hexokinase activity, it does not quantitatively indicate to what extent this step is responsible for the reduced rate of glycogen synthesis. If the defect in muscle glucose transport/hexokinase contributes to the reduced rate of glycogen synthesis in NIDDM, an increase in the activity of this step would increase the rate of glycogen synthesis. In the high-dose insulin clamp the glucose uptake rate, the majority of which is accounted for under these conditions by muscle glycogen synthesis (1), was raised in four diabetic subjects to the level of the normal subjects in the lowdose insulin clamp. This increase in glucose uptake was associated with a rise in G6P concentration, indicating an increase in transport/hexokinase activity which supports a role for this step in reducing the rate of glycogen synthesis. A correlation between increased glucose uptake and muscle G6P concentration as a function of plasma insulin concentration has been demonstrated in normal and partially pancreatectomized rats (15). Additional evidence for this hypothesis is that the normal subjects had both a greater transport/hexokinase activity and rate of nonoxidative glucose metabolism than the diabetic subjects in the low-dose insulin study.

A contribution of a defect in glycogen synthase to the reduced muscle glycogen synthesis rate in NIDDM is not ruled out by our findings. Under hyperinsulinemic conditions a positive correlation has been found between the activity of semipurified glycogen synthase and the rate of nonoxidative glucose metabolism in normal subjects and subjects with NIDDM (58 , 14). However, at physiological insulin concentrations similar to the present low-dose insulin study, the correlation is weaker than at maximally stimulating insulin concentrations which is consistent with a defect in transport/hexokinase contributing to the reduced rate.

The reduced transport/hexokinase activity in NIDDM can potentially exert control over the glycogen synthase rate by reducing the levels of intracellular glucose and G6P. Studies that have assayed semipurified synthase enzyme obtained from human subjects under hyperinsulinemic conditions have found a $K_{\mathrm{m}}$ for allosteric stimulation by G6P in the $0.10 \mathrm{mmol} /$ liter range $(14,32)$, which is similar to the concentrations mea- sured in muscle. A role of allosteric stimulation by G6P in determining the glycogen synthase rate is supported by the finding of a lower concentration of G6P in the NIDDM group in the low-insulin study. Lower concentrations of intracellular glucose due to a transport defect may inhibit the conversion of synthase to the active form by synthase phosphatase. Studies have found that at insulin levels similar to the low-dose study ( $\sim 450 \mathrm{pmol} /$ liter) the assayed activity of the synthase enzyme in normal and diabetic subjects $(33,34)$ increases with higher plasma glucose concentration. An increase in plasma glucose concentration should have a similar effect on glycogen synthase as an increase in glucose transporter activity in that both result in a greater influx rate of plasma glucose into muscle.

The lower concentration of G6P in the NIDDM subjects may be due to a reduction in the activity of either or both glucose transport and hexokinase. Studies of isolated adipocytes, which have the same insulin-stimulated GLUT 4 transporter as muscle (12), provide support for the defect as being in transport based on findings of reduced insulin-stimulated glucose transport and glucose transporter enzyme number in adipocytes isolated from subjects with NIDDM (9-11). However, no reduction in GLUT 4 or GLUT 1 mRNA or protein has been found in the muscle of subjects with NIDDM (35). Reduced transport despite a constant number of transporters may be due to a defect in translocation, which would result in fewer transporters in the muscle plasma membrane. Alternatively, a reduction in glucose transport in NIDDM may be the result of impaired glucose or insulin delivery from the blood owing to reduced blood flow (36) or muscle capillary density (37).

The results of the present study do not provide information on whether the defect in glucose transport or hexokinase is an initial defect in the pathogenesis of NIDDM. Long-term exposure to hyperglycemia has been shown to reduce insulin-stimulated nonoxidative metabolism in rats (38) and insulin-dependent diabetic humans (39) and may account for the reduced transport/hexokinase activity in the subjects with NIDDM. However, studies on populations and families with a high incidence of NIDDM have shown a strong correlation between reduced insulin-dependent nonoxidative glucose metabolism and the later development of $\operatorname{NIDDM}(40,41)$. This reduction in nonoxidative glucose metabolism occurs before the hyperglycemia and alterations in postprandial insulin production that accompany NIDDM. Whether the decrease in nonoxidative glucose metabolism in these individuals is also accompanied by a decrease in glucose transport/hexokinase activity remains to be determined.

In conclusion, the finding under conditions of hyperglycemic hyperinsulinemia of a lower muscle G6P concentration and a reduced rate of nonoxidative glucose metabolism in subjects with NIDDM indicates a reduction in the activity of either muscle glucose transport or hexokinase. The correlation found in the low- and high-dose insulin studies between higher G6P concentrations, which reflect increased transport activity, and an increased rate of nonoxidative glucose metabolism is consistent with this defect's being an important determinant of the lower rate of insulin-dependent muscle glycogen synthesis in NIDDM.

\section{Acknowledgments}

We are indebted to the nurses and staff of the Yale/New Haven Hospital General Clinical Research Center, Dr. Peter Stein for patient re- 
cruitment, Dr. Thomas Price for design and construction of the NMR probe, Dr. Julie Pan and Dr. Li-Hsin Zang for assistance with the assignment of G6P, Mr. Terence Nixon for maintaining and technical upgrades of the NMR spectrometer, and Mr. Mark D. Luffburrow and Mr. Robbe Mellencamp for technical assistance.

This work was supported by National Institute of Health grants DK-34576, DK-40936, and M01-RR-00125-26.

\section{References}

1. Shulman, G. I., D. L. Rothman, T. Jue, P. Stein, R. A. DeFronzo, and R. G. Shulman. 1990. Quantitation of muscle glycogen synthesis in normal subjects and subjects with noninsulin-dependent diabetes by ${ }^{13} \mathrm{C}$ nuclear magnetic resonance spectroscopy. $N$. Engl. J. Med. 322:223-228.

2. DeFronzo, R. A., E. Jacot, E. Jequier, E. Maeder, J. Wahren, and J. P. Felber. 1981. The effect of insulin on the disposal of intravenous glucose: results from indirect calorimetry and hepatic and femoral venous catheterization. Diabetes. 30:1000-1007.

3. Thiebaud, D., E. Jacot, R. A. DeFronzo, E. Maeder, E. Jequier, and J. P. Felber. 1982. The effect of graded doses of insulin on total glucose uptake, glucose oxidation, and glucose storage in man. Diabetes. 31:957-963.

4. Felber, J. P., A. Golay, C. Felley, and E. Jequier. 1988. Regulation of glucose storage in obesity and diabetes: metabolic aspects. Diabetes Metab. Rev. 4:691-700.

5. Roch-Norland, A. E., J. Bergstrom, and E. Hultman. 1972. Muscle glycogen and glycogen synthetase in normal subjects and in patients with diabetes mellitus: effect of intravenous glucose and insulin administration. Scan. J. Clin. Invest. 30:77-84.

6. Bogardus, C., S. Lillioja, K. Stone, and D. Mott. 1984. Correlation between muscle glycogen synthase activity and in vivo insulin action in man. J. Clin. Invest. 73:1185-90.

7. Mandarino, L. J., K. S. Wright, L. S. Verity, J. Nichols, J. Bell, O. G. Kolterman, and H. Beck-Nielsen. 1987. Effects of insulin infusion on human skeletal muscle pyruvate dehydrogenase, phosphofructokinase, and glycogen synthase: evidence for their role in oxidative and non oxidative glucose metabolism. J. Clin. Invest. 80:655-663.

8. Freymond, D., C. Bogardus, M. Okubo, K. Stone, and D. Mott. 1988. Impaired insulin stimulated muscle glycogen synthase activation in vivo in man is related to low fasting glycogen synthase phosphatase activity. J. Clin. Invest. 82:1503-1509.

9. Ciaraldi, T. P., O. G. Kolterman, J. A. S. Scarlett, M. Kao, and J. M. Olefsky. 1982. Role of glucose transport in the postreceptor defect of non-insulindependent diabetes mellitus. Diabetes. 31:1016-1022.

10. Kashiwagi, A., M. Antonia Verso, J. Andrews, B. Vasquez, G. Reaven, and J. E. Foley. 1983. In vitro insulin resistance of human adipocytes isolated from subjects with noninsulin-dependent diabetes mellitus. J. Clin. Invest. 72:1246-1254.

11. Foley, J. E., P. Thuillez, S. Lillioja, J. Zawadzki, and C. Bogardus. 1986. Insulin sensitivity in adipocytes from subjects with varying degrees of glucose tolerance. Am. J. Physiol. 251(Endocrinol. Metab. 14):E306-310.

12. James, D. E., M. Strube, and M. Mueckler. 1989. Molecular cloning and characterization of an insulin regulatable glucose transporter. Nature (Lond.). 33:83-87.

13. Young, A. A., C. Bogardus, K. Stone, and D. M. Mott. 1988. Insulin responses of components of whole-body and muscle carbohydrate metabolism in humans. Am. J. Physiol. (Endocrinol. Metab. 17):E231-236.

14. Yki-Jarvinen, H., K. Sahlin, J. M. Ren, and V. A. Koivisto. 1990. Localization of rate limiting defect for glucose disposal in skeletal muscle of insulin resistant type I diabetic patients. Diabetes. 39:157-167.

15. Rossetti, L., and A. Giaccari. 1990. Relative contribution of glycogen synthesis and glycolysis to insulin mediated glucose uptake: a dose response study. J. Clin. Invest. 85:1785-1792.

16. Gadian, D. G., G. K. Radda, R. E. Richards, and P. J. Seeley. 1979. ${ }^{31} \mathrm{P}$ NMR in living tissue: the road from a promising tool to an important tool in biology. In Biological Applications of Magnetic Resonance. R. G. Shulman ed. Academic Press, Inc., New York. 463-536.

17. Taylor, D. J., P. Styles, P. M. Matthews, D. A. Arnold, D. G. Gadian, P. Bore, and G. K. Radda. 1986. Energetics of human muscle: exercise-induced ATP depletion. Magn. Reson. Med. 3:44-54.

18. National Diabetes Data Group. 1979. Classification and diagnosis of dia- betes mellitus and other categories of glucose intolerance. Diabetes. 28:10391057.

19. DeFronzo, R. A., J. E. Tobin, and R. Andres. 1979. Glucose clamp techniques: a method for quantifying insulin secretion and resistance. Am.J. Physiol. 237:E214-E233.

20. DeFronzo, R. A., E. Ferrannini, R. Hendler, J. Wahren, and P. Felig. 1978. Influence of hyperinsulinemia, hyperglycemia, and the route of glucose administration on splanchnic glucose exchange. Proc. Natl. Acad. Sci. USA. 75:5173-5177.

21. Lusk, G. 1924. Animal calorimetry: analysis of the oxidation of mixtures of carbohydrate and fat: a correction. J. Biol. Chem. 59:41-42.

22. Rosselin, G. R., S. Assan, R. S. Yalow, et al. 1966. Separation of antibodybound and unbound peptide hormones labelled with iodine- $I^{131}$ by talcum powder and precipitated silica. Nature (Lond.). 212:355-357.

23. Gordon, R. E., P. E. Hanley, and D. Shaw. 1982. Topical magnetic resonance. Prog. Nucl. Magn. Reson. Spectrosc. 15:1-47.

24. Harris, R. C., E. Hultman, and L. O. Nordesjo. 1974. Glycogen, glycolytic intermediates and high energy phosphates determined in biopsy samples of musculus quadriceps femoris of man at rest: Methods and variance of values. Scand. J. Clin. Lab. Invest. 33:109-120.

25. Petroff, O. A. C., J. W. Prichard, K. L. Behar, J. R. Alger, J. A. den Hollander, and R. G. Shulman. 1985. Cerebral intracellular pH by ${ }^{31} \mathrm{P}$ nuclear magnetic resonance spectroscopy. Neurology. 35:781-788.

26. Lawson, J. W. R., and R. L. Veech. 1979. Effects of $\mathrm{pH}$ and free $\mathrm{Mg}^{2+}$ on the $\mathrm{K}_{\mathrm{eq}}$ of the creatine kinase reaction and other phosphate hydrolyses and phosphate transfer reactions. J. Biol. Chem. 254:6528-6537.

27. Lueck, J. D., and H. J. Fromm. 1975. Kinetics, mechanism, and regulation of rat skeletal muscle hexokinase. J. Biol. Chem. 249:2259-2268.

28. Maehlum, S., A. T. Hostmark, and L. Hermansen. 1977. Synthesis of muscle glycogen during recovery after prolonged severe exercise in diabetic and non-diabetic subjects. Scand. J. Clin. Lab. Invest. 37:309-316.

29. Danforth, W. H. 1965. Glycogen synthetase activity in skeletal muscle: interconversion of two forms and control of glycogen synthesis. J. Biol. Chem. 240:588-593.

30. Piras, R., and R. Staneloni. 1969. In vivo regulation of rat muscle glycogen synthetase activity. Biochemistry. 8:2153-2160.

31. Chance, B., S. Eleff, J. S. Leigh, D. Sokolow, and A. Sapega. 1981. Mitochondrial regulation of phosphocreatine/inorganic phosphate ratios in exercising human muscle: a gated ${ }^{31} \mathrm{P}$ NMR study. Proc. Natl. Acad. Sci. USA. 78:67146718.

32. Guinovart, J. J., A. Salavert, J. Massague, C. J. Ciudad, E. Salsas, and E. Itarte. 1979. Glycogen synthase: a new activity ratio assay expressing a high sensitivity to the phosphorylation state. FEBS (Fed. Eur. Biochem. Soc.) Lett. 106:284-288.

33. Yki-Jarvinen, H., D. Mott, A. A. Young, K. Stone, and C. Bogardus 1987. Regulation of glycogen synthase and phosphorylase activities by glucose and insulin in human skeletal muscle. J. Clin. Invest. 80:95-100.

34. Kelley, D. E., and L. J. Mandarino. 1990. Hyperglycemia normalizes insulin-stimulated skeletal muscle glucose oxidation and storage in noninsulindependent diabetes mellitus. J. Clin. Invest. 86:1999-2007.

35. Pedersen, O., J. F. Bak, P. H. Andersen, S. Lund, D. E. Moller, J. S. Flier, and B. B. Kahn. 1990. Evidence against altered expression of GLUT1 or GLUT4 in skeletal muscle of patients with obesity or NIDDM. Diabetes. 39:865-870.

36. Laakso, M., S. V. Edelman, G. Brechtal, and A. D. Baron. 1990. Decreased effect of insulin to stimulate skeletal muscle blood flow in obese man. a novel mechanism for insulin resistance. J. Clin. Invest. 85:1844-1852.

37. Lillioja, S., A. A. Young, C. L. Culter, J. L. Ivy, W. G. H. Abbott, J. K Zawadzki, H. Yki-Jarvinen, L. Christin, T. W. Secomb, and C. Bogardus. 1987. Skeletal muscle capillary density and fiber type are possible determinants of in vivo insulin resistance in man. J. Clin. Invest. 80:415-424.

38. Rossetti, L., D. Smith, G. I. Shulman, D. Papachristou, and R. A. DeFronzo. 1987. Correction of hyperglycemia with phlorizin normalizes tissue sensitivity to insulin in diabetic rats. J. Clin. Invest. 79:1510-1515.

39. Yki-Jarvinen, H., E. Helve, and V. A. Koivisto. 1987. Hyperglycemia decreases glucose uptake in type I diabetes. Diabetes. 36:892-896.

40. Lillioja, S., D. M. Mott, B. V. Howard, P. H. Bennett, H. Yki-Jarvinen, D. Freymond, B. L. Nyomba, F. Zurlo, B. Swinburn, and C. Bogardus. 1988. Impaired glucose tolerance as a disorder of insulin action: longitudinal and crosssectional studies in Pima Indians. $N$. Engl. J. Med. 318:1217-1225.

41. Eriksson, J., A. Franssila-Kallunki, A. Ekstrand, C. Saloranta, E. Widen, C. Schalin, and L. Groop. 1989. Early metabolic defects in persons at increased risk for non-insulin-dependent diabetes mellitus. N. Engl. J. Med. 321:337-343. 